\title{
A invenção estratégica do terceiro sector como estrutura de observação mútua: Uma abordagem histórico-conceptual
}

The Strategic Invention of the Third Sector as a Structure for Mutual Observation: A Historical-conceptual Approach

L'invention stratégique du tiers secteur en tant que structure d'observation mutuelle: un abordage historico-conceptuel

\section{Sílvia Ferreira}

\section{OpenEdition}

\section{Journals}

Edição electrónica

URL: http://journals.openedition.org/rccs/422

DOI: $10.4000 /$ rccs.422

ISSN: $2182-7435$

\section{Editora}

Centro de Estudos Sociais da Universidade de Coimbra

Edição impressa

Data de publição: 1 Março 2009

Paginação: 169-192

ISSN: 0254-1106

Refêrencia eletrónica

Sílvia Ferreira, «A invenção estratégica do terceiro sector como estrutura de observação mútua: Uma abordagem histórico-conceptual », Revista Crítica de Ciências Sociais [Online], 84 | 2009, colocado

online no dia 01 outubro 2012, criado a 19 abril 2019. URL : http://journals.openedition.org/rccs/422 ; DOI : $10.4000 /$ rccs. 422 


\section{SÍLVIA FERREIRA}

\section{A invenção estratégica do terceiro sector como estrutura de observação mútua: Uma abordagem histórico-conceptual}

Este texto analisa o campo discursivo do terceiro sector e os seus actores sociais a partir da articulação teórica entre a abordagem relacional estratégica, a teoria dos sistemas complexos autopoiéticos e a cibernética. Centrando-se no conceito de observação, o texto desenvolve-se em quatro argumentos sobre o terceiro sector. Primeiro, é um "campo discursivo", onde discursos e práticas reflectem e moldam as selectividades estruturais e as estratégias dos actores. Segundo, é uma categoria relacional, sendo construído através de um conjunto de relações que se estabelecem entre diferentes modos de organização das relações sociais. Terceiro, é contextual, sendo moldado pelas configurações espácio-temporais das sociedades em que se constitui e das condições concretas em que se dá a transição do fordismo para o pós-fordismo. Quarto, a semântica do terceiro sector e as organizações e interacções que o povoam põem em interacção relações sociais típicas dos diferentes modos de coordenação ou diferentes subsistemas, permitindo a observação mútua.

Palavras-chave: Terceiro sector, economia social e solidária, observação, complexidade.

\section{Introdução}

No início dos anos 1970, emergiu um novo actor nas discussões do Estado-Providência, o terceiro sector, assim chamado por ser descrito como incluindo organizações e práticas descritas como não sendo do Estado nem do mercado. Desde os anos 1990 este sector tem vindo a crescer em termos de visibilidade e importância e a ser visto quer como actor económico (fonte de emprego e empreendedorismo, capaz de satisfazer necessidades dos consumidores e gerar riqueza), quer como actor político (promotor da cidadania e da capacitação, e parceiro do Estado na governação local) (Amin et al., 2002: 2). Não é que organizações, práticas, redes, teorias e quadros legais não existissem anteriormente, mas não eram equacionados num sector. Desde que foi "inventado", actores do sector, investigadores, actores governamentais e outros têm-se dedicado a desenhar fronteiras e a identificar 
híbridos, de modo que a discussão das fronteiras do terceiro sector tem sido uma constante. Neste e em outros aspectos, o "sector" é um produto da complexidade contemporânea, reflectindo os desenvolvimentos do Estado-Providência, bem como da sua crítica e crise (Santos, 2006). Assim se torna compreensível o paradoxo apontado por Kramer (1998), segundo o qual a ideia de sector emerge num momento em que as fronteiras tradicionais entre público e privado se esbatem:

Entre termos alternativos usados correntemente, em lugar da dicotomia tradicional público/privado existe: pluralismo de bem-estar, economia mista ou nova economia política, o Estado contratual, o estado capacitador, o Estado-sombra, o governo por terceiros e a administração pública indirecta. Por sua vez, estes são vistos como o resultado de fronteiras descritas como ambíguas, distorcidas, desaparecendo, dissolvendo-se, misturando-se, desintegrando-se, fundindo-se, mudando, erodindo, desaparecendo e sobrepondo-se. (Kramer, 1998: 12) ${ }^{1}$

Neste texto, o meu argumento possui quatro momentos, sendo a partir destes que se desenvolve. Primeiro, o terceiro sector é um "campo discursivo", onde discursos e práticas reflectem e moldam as selectividades estruturais e as estratégias dos actores. Segundo, o terceiro sector é uma categoria relacional, sendo construído através de um conjunto de relações que se estabelecem entre diferentes modos de organização das relações sociais, tipicamente associados ao Estado, à economia de mercado, à comunidade e à sociedade civil. Terceiro, o terceiro sector é contextual, pois não só é uma forma de organizar relações típicas dos modos de coordenação das relações sociais na transição do fordismo para o pós-fordismo, como é moldado pelas configurações espácio-temporais das sociedades em que se constitui e das condições concretas em que se dá esta transição. Quarto, na sua lógica dominante de organização, o terceiro sector, mas também as organizações e interacções que o constituem, põe em interacção relações sociais típicas dos diferentes modos de coordenação ou diferentes subsistemas, permitindo a observação mútua.

A minha análise propõe a articulação da abordagem relacional estratégica desenvolvida por Jessop (2007) com contributos provenientes das teorias dos sistemas complexos e da cibernética articulados por Luhmann (1995a) e outros autores. Enquanto da primeira retiro a ideia do modo como estratégias e estruturas se co-constituem, dos segundos retiro os pressupostos sobre sistemas autopoiéticos e o conceito de observação. A abordagem relacional

\footnotetext{
${ }^{1}$ Esta e outras citações neste texto são traduções minhas.
} 
estratégica afirma que determinadas estruturas reforçam formas de acção, tácticas e estratégias específicas e desencorajam outras, ou seja, têm selectividades estratégicas estruturalmente inscritas. Do lado da acção, o conceito de cálculo estratégico orientado estruturalmente descreve o facto de que os actores sociais têm capacidade de reflectir sobre as selectividades estruturais e orientar as suas estratégias e tácticas. Assim, os actores sociais são estratégicos de modo a fazer avançar os seus interesses tendo em conta a forma como concebem as oportunidades de uma determinada estrutura (Jessop, 2007).

Os conceitos de observação e de observações de primeira e de segunda ordem permitem descrever as operações de redução de complexidade que tornam possível agir no mundo a partir do concreto complexo e das observações deste. São estes conceitos que guiam a minha descrição dos processos de "invenção" estratégica de um sector focando as suas auto e heterodescrições. Para Spencer Brown (1969), a observação é o conceito básico a partir do qual coisas, pensamentos, acções e comunicações podem ser compreendidos. Qualquer observação cria uma distinção entre o que é observado e o que não é observado (espaço marcado e não marcado). O que não é seleccionado para observação não pode ser percebido pelo observador. A ideia de que uma observação indica não apenas o espaço marcado, mas também o que é excluído é importante porque sugere que qualquer observação torna possível a observação do que é excluído a um segundo nível. Isto leva-nos ao paradoxo da auto-referencialidade, que acontece quando as condições de possibilidade de uma operação são, ao mesmo tempo, as suas condições de impossibilidade (Luhmann, 1995b). A observação de segunda ordem, trazida pela cibernética de segunda ordem, permite observar os paradoxos das selecções pois, ao indicar os dois lados da forma da observação, cria também a oportunidade para a observação das exclusões dessa forma.

Qualquer observação, ao mesmo tempo que reduz a complexidade do mundo, aumenta-a porque acrescenta à complexidade ontológica o impacto das suas selecções. Assim, ao mesmo tempo que a diferenciação dos sistemas autopoiéticos complexos é uma estratégia que permite lidar com a complexidade através do fechamento operacional que distingue sistema e ambiente, as selectividades inscritas neste fechamento geram mais complexidade dada a exteriorização de um número crescente de operações e impactos para o seu ambiente. Os resultados da complexidade criada pelas observações de um sistema podem ser equacionadas como fracassos, quer sob o ponto de vista do sistema que faz a observação de primeira ordem, quer do ponto de vista de um sistema que observa estas selecções, quer ainda do de uma observação das observações (como a da contingência das distinções criadas pelas observações). 
Focarei a semântica de terceiro sector e suas autodescrições, concebendo a semântica como formas de sentido, observações e partes de observações que são preservadas pelos sistemas para uso repetido com objectivos de comunicação, ou seja, selecções que limitam o sentido de modo a possibilitar comunicação (Luhmann, 1995a: 163). Analisar a semântica implica estudar "o modo como o sentido é criado, fixado e condensado na forma de novos conceitos, mudanças nos conceitos e nas suas relações, incluindo a substituição dos contra-conceitos dos conceitos, etc.” (Andersen, 2000: 6).

A utilização do conceito de observação neste texto tem dois significados. Por um lado, posiciono-me como observadora de segunda ordem, observando as observações do sector através das suas diversas semânticas e observações mútuas estrategicamente construídas. Por outro lado, analiso o terceiro sector, as suas organizações e interacções como observação de segunda ordem, dado o modo como articulam observações do Estado, do mercado e da comunidade e se oferecem como estrutura possibilitando observações mútuas.

\section{A invenção do terceiro sector}

O terceiro sector, enquanto abstracção, encontra-se em lugares particulares como observações que designam uma parte do mundo e traçam as fronteiras do que lhe pertence e do que lhe não pertence. O primeiro lugar é povoado pelas organizações de segundo grau ou de graus superiores, redes e plataformas, e outras estruturas que agregam organizações, grupos, indivíduos autónomos e distintos ao nível local, regional, nacional ou internacional que produzem e reproduzem a semântica do sector. O segundo lugar é o dos cientistas sociais, do seu papel, dos seus projectos, centros de investigação e revistas científicas, que, através das actividades de definição, classificação e mensuração, desenham os contornos do "sector". O terceiro lugar encontra-se nas políticas públicas que designam e regulam o sector e lhe reservam um papel na governação societal, nos departamentos governamentais dedicados ao "sector" ou nas relações entre o "sector" e as políticas e as outras esferas de actividade governativa. Estes três lugares de "invenção" do sector estão frequentemente em relação directa, produzindo cooperativamente ou concorrencialmente o "sector", ou em desacordo sobre aspectos relacionados com o "sector". Aqui, tal como acontece a níveis mais concretos, as observações que constituem o terceiro sector são também contextuais e estratégicas. O terceiro sector emerge da conjugação histórica de relações e eventos que moldam as possibilidades de uma determinada observação do sector ter ressonância em determinadas estruturas sociais. 
Há dois aspectos a ter em conta na análise histórica da "invenção" do sector. Um é o surgimento do termo, o contexto deste surgimento e os discursos a ele associados. Outro é a estruturação ${ }^{2}$ de um campo social que se inventou (e foi inventado) como sector, composto por um tipo específico de relações sociais, organizações e princípios, e o significado estratégico desta construção para diferentes actores sociais. O surgimento da ideia de um sector entre o Estado e o mercado ocorreu simultaneamente em diferentes países, mas o sentido de terceiro sector é distinto, implicando observações diferentes de país para país e até no mesmo país. Nos países em que tal ocorreu existe uma coincidência de mobilização de determinadas organizações - no sentido de produzir estrategicamente a ideia de um sector abrangente -, de investigadores e pensadores - no sentido de identificar os aspectos comuns destas iniciativas - e de iniciativas políticas - no sentido de identificar o papel (ou funções) deste "sector" nos objectivos estatais.

Nos Estados Unidos, Theodor Levitt (1973) usou o termo para descrever uma grande variedade de iniciativas e organizações entre o público e o privado, e fora do mercado e do Estado. De acordo com o autor, estas iniciativas faziam, ou exigiam que fosse feito, aquilo que o Estado e o mercado não faziam, não faziam bem ou não faziam com frequência suficiente... Em França, as primeiras referências ao termo foram relacionadas com a crise do emprego e a crítica da relação salarial fordista, e inspiradas pelas iniciativas de autonomia no trabalho (travailler autrement) que emergiram em 1968 (Delors, 2004).

A “invenção" de um sector não adoptou sempre a semântica de terceiro sector, mas designações locais que deram expressão a tradições nacionais. O que é importante, porém, é que, em alguns países, um sector foi estrategicamente criado, frequentemente a partir do impulso de organizações que dele faziam parte. É no contexto desta movimentação que se cria em 1973, nos EUA, a Commission on Private Philantbropy and Public Needs (Filler Commission) para estudar e fazer avançar a contribuição do terceiro sector, produzindo o relatório "Giving in America". É então que se estabelece uma associação de cúpula, chamada Independent Sector, se constrói uma identidade baseada no estatuto legal de organizações não lucrativas e surgem estudos, sobretudo da economia, justificando a existência de um sector para responder aos fracassos do mercado ou do Estado. Em 1971, surge a Asso-

\footnotetext{
${ }^{2}$ Refiro-me aqui à forma como DiMaggio e Powell (1983: 148) concebem a estruturação de um determinado campo institucional. Os autores descrevem-na como um processo em quatro fases: aumento da interacção entre as organizações; emergência de estruturas inter-organizacionais de dominação e de coligações; aumento do volume da informação; desenvolvimento de uma consciência mútua entre os participantes, concebendo-se como envolvidos num projecto comum.
} 
ciation for Voluntary Action Scholars e, em 1972, a sua revista científica, Journal for Voluntary Action Research. Também no Reino Unido se inventou um "sector" em finais dos anos 1970 (Kendall, 2000), invenção essa marcada pelo estabelecimento de uma comissão que, no contexto de crítica ao modelo Beveridgiano de bem-estar (por insuficiência) ou ao Estado-Providência (por excesso), publicou o relatório The Future of Voluntary Organisations (Wolfenden Committee, 1978). Este relatório constrói a sua argumentação a partir da ideia de que existem quatro sectores - estatal, comercial, voluntário e informal -, cujas características e papéis se definem relacionalmente, enquadrados por uma perspectiva de "pluralismo de bem-estar". Defourny e Campos (1992) também descrevem a reemergência da economia social em França. É neste contexto que, em 1986, uma revista dedicada aos estudos cooperativos é rebaptizada de Revue des études coopératives, mutualistes et associatives (RECMA). Estes esforços foram também apoiados por académicos, que se dedicaram à releitura dos pensadores e doutrinadores do século XIX e inícios do século XX, o que ajuda a perceber a razão pela qual a ideia de economia social se funda na noção de que existem outras formas de organizar as relações económicas para além do mercado (Evers e Laville, 2004).

A década de 1990 foi de institucionalização e globalização do "sector", com um acréscimo significativo de pesquisa e de publicações, de lançamento de centros de pesquisa e de revistas, de criação de associações nacionais e internacionais de investigadores, com relevo para a International Society for Third Sector Research (ISTR) e a sua revista Voluntas. Surgem estudos comparativos internacionais que contribuíram para criar a ideia da importância do sector e do seu crescimento graças ao esforço de classificação e definição de indicadores quantitativos passíveis de recolha nos diferentes países. O Projecto Comparativo do Sector Não Lucrativo da Universidade Johns Hopkins, nos EUA, é uma referência significativa, tendo desenvolvido uma definição estrutural operativa focada em características organizacionais - organizações formais, autogovernadas, privadas, não-lucrativas e voluntárias - e uma classificação de acordo com áreas de actividade (INCPO). ${ }^{3}$ Desde que começou, em 1995, este projecto foi levado a cabo em 41 países (Salamon et al., 1999 e 2004), ${ }^{4}$ tendo, em alguns casos, permitido os primeiros estudos nacionais abrangentes e possibilitado comparações internacionais. Estas classificações e indicadores permitem que o sector se torne observável para os sistemas económico e político, pois é medido em termos

\footnotetext{
${ }^{3}$ International Classification of Non-profit Organisations (ICNPO). Ver Salamon e Anheier, 1992.

${ }^{4}$ Ver também http://www.jhu.edu/ cnp/.
} 
do número de trabalhadores (remunerados ou voluntários) e em horas equivalentes a tempo inteiro (ETI), sendo também recolhidos dados relativos às receitas e ao peso das várias fontes de financiamento das organizações - governo, filantropia, vendas. Os dados permitem afirmar a existência de um sector com um peso significativo em termos de emprego e argumentar a favor de políticas de apoio ao contributo do sector para a resolução dos problemas de emprego e do fracasso das políticas sociais.

O impacto deste Projecto vai para além dos meios académicos ou da produção de estatísticas que fundamentam estratégias de afirmação. Em colaboração com a divisão de estatística das Nações Unidas elaborou um Manual para a inserção do contributo do terceiro sector nas contas nacionais dos países, lado a lado com o sector público e o sector privado lucrativo. De acordo com o sítio do projecto na Internet, ${ }^{5}$ são já 31 os países interessados em adoptá-lo, contando com o apoio de agências como o Eurostat e a Direcção de Estatística da OCDE, entre outras.

\section{Observações alternativas do terceiro sector}

Como afirmei anteriormente, qualquer observação torna possível a observação das exclusões operadas por essa mesma observação. O Projecto da Johns Hopkins foi criticado por se centrar nas organizações mais formais, burocratizadas e profissionalizadas, frequentemente prestando serviços subcontratados pelo Estado. Isto, argumentam outros autores, não tem suficientemente em conta as organizações comunitárias ou de base ou os grupos de auto-ajuda, de carácter mais informal, maioritariamente sustentados por voluntários e com um elevado número de associados que não são observados nas estatísticas (Smith, 2000: 30).

Também no Reino Unido surgiram dois relatórios concorrentes apresentando observações distintas do "sector". Um destes relatórios, designado correntemente de Centris Report (Knight, 1993), optou pela estratégia de dividir o sector em dois, a que chamou primeira e terceira forças. Caracterizou o conjunto de iniciativas que fazem parte da primeira força como “acção voluntária autêntica, profética, guiada por uma visão reformista, independente do governo, prosseguindo uma energia independente tendo em vista objectivos morais", enquanto a terceira força seria composta pelas organizações agindo filantropicamente ou subcontratadas pelo Estado, "organizada através de empresas não lucrativas que têm que se conformar com critérios de operação consensuais, como sejam igualdade de oportu-

${ }^{5}$ Handbook on Nonprofit Institutions in the System of National Accounts (http://www.jhu.edu/ ccss/unhandbook/). 
nidades ou preocupações ambientais" (Knight, 1993: xi-xii). Esta divisão do sector e a proposta de retirar o apoio financeiro governamental à primeira força para a manter independente tinham como pano de fundo propostas do governo no sentido de generalizar à relação entre o Estado e as organizações voluntárias as lógicas da relação entre o Estado e as empresas nas actividades financiadas publicamente. Porém, sendo uma estratégia de defesa da primeira força, a divisão do sector atingia os interesses das organizações da "terceira força". É neste sentido que surge um relatório alternativo, o Deakin Report (Commission on the Future of the Voluntary Sector, 1996), promovido por uma das organizações federativas, que insiste na observação de três sectores e defende a heterogeneidade existente no interior do sector e dentro das próprias organizações de forma a evitar a dualização. Torna-se evidente que as observações do sector são uma forma de governação do mesmo, sendo também palco de disputas estratégicas que envolvem a própria sustentabilidade das organizações.

Uma outra observação é a da economia social, que, como já foi referido, surge por efeito de observações específicas na Europa continental. O conceito de economia social também se autodescreve como uma observação alternativa à observação do terceiro sector a partir de outras observações específicas: enquanto a observação do sector não lucrativo ou do terceiro sector se centra na lucratividade, a observação da economia social centra-se nos direitos de propriedade, pois o primeiro critério leva à exclusão de um número elevado de cooperativas e mutualidades. Para estes investigadores, a "linha de demarcação não deve ser desenhada entre organizações lucrativas e não lucrativas mas, sim, entre organizações capitalistas e organizações da economia social, estas últimas centradas na geração de riqueza colectiva em vez de rendimento a um investimento individual" (Laville et al., 2000: 102).

Existe, pois, na Europa continental, uma tentativa de identificação de uma esfera de organizações e princípios de conotação europeia, igualmente com as suas organizações de cúpula, os seus centros de investigação e os seus investigadores. É de assinalar o papel desempenhado pelo CIRIEC (Centre International de Recherches et d'Information sur l'Economie Publique, Sociale et Coopérative), que observa a partir da fronteira entre a economia pública e cooperativa e a economia privada. Este Centro tem tido um papel proeminente no mapeamento desta esfera de organizações e actividades na Europa e no mundo, nomeadamente através de projectos financiados por instituições europeias, ${ }^{6}$ questionando também a terminologia de

\footnotetext{
${ }^{6}$ O estudo mais recente, encomendado pelo Comité Económico e Social, analisa a economia social nos então 25 países da União Europeia (Ávila e Monzón Campos, 2006).
} 
sector por implicar uma observação de separações entre Estado, mercado e terceiro sector e, em particular, a ideia de antagonismo entre o Estado e o terceiro sector, subjacente a alguma teorização anglo-saxónica. O CIRIEC também intervém no desenho de uma conta satélite para o Sistema Europeu de Contas Nacionais e Regionais e surge como uma observação alternativa para incluir a tradição europeia, complementando a conta satélite das Nações Unidas. ${ }^{7}$

Existem também observações alternativas à observação da economia social, chamadas de nova economia social, empresa social ou economia solidária, que apontam para observações idênticas do que é excluído nas observações da economia social - inovação organizacional, participação dos utilizadores e eficácia - e propõem fronteiras alternativas. Observando a velha economia, Chanial e Laville (2005:59) argumentam que, desde finais do século XIX e no decurso do século XX, se verificou uma "domesticação através do direito" das iniciativas dos movimentos de trabalhadores, que passou pela sua fragmentação com vista à sua inserção no sistema económico, nomeadamente com a criação dos estatutos separados de cooperativas, mutualidades e associações. Com estes estatutos jurídicos, estas iniciativas integraram o modelo de desenvolvimento económico e social baseado na separação entre Estado e mercado.

As empresas sociais são descritas como ultrapassando as fronteiras entre as cooperativas, associações e mutualidades em termos de forma organizacional e áreas de actividade tradicionais. Trata-se, portanto, de uma observação sobre as fronteiras criadas por estas observações, tendo também os seus actores próprios, nomeadamente numa rede europeia de investigadores constituída para estudar as empresas sociais, a rede EMES (Borzaga e Defourny, 2001). Com o nome de empresas sociais existe uma descrição com uma ênfase distinta, nomeadamente nos Estados Unidos e no Reino Unido, de maior aproximação ao mercado, através de uma apropriação selectiva de aspectos típicos das empresas lucrativas, mantendo-se distintas nos seus objectivos sociais (Young, 2003). Esta é também uma ideia que surge com o conceito de empreendedorismo social que igualmente contém duas observações distintas, uma de aproximação às técnicas das empresas e outra com enfoque na transformação social (Ferreira, 2005).

O conceito de economia solidária não recobre necessariamente a ideia de empresa social, ainda que existam pontos de sobreposição em termos da descrição. O conceito centra-se na observação da diferença capita-

\footnotetext{
${ }_{7}$ Manual for Drawing up the Satellite Accounts of Companies in the Social Economy (Barea e Monzón Campos, 2006).
} 
lista/não capitalista. No Brasil, onde tem importante ancoragem institucional e académica, descreve iniciativas associativas e autogestionárias por parte de trabalhadores, onde "combinam-se atividades produtivas com atividades de cunho social e educativo, centradas, umas e outras, nos valores do solidarismo e da reciprocidade" (Gaiger, 2000: 3) e onde a forma é variável, incluindo associações informais, grupos de produção familiar, cooperativas de trabalhadores, pequenas e médias empresas autogeridas. Como refere Gaiger, "Contrapondo-se ao conservadorismo político e ao perfil empresarial do cooperativismo tradicional, novas cooperativas de trabalhadores têm surgido nos segmentos de consumo, produção, comercialização e serviços" (2000: 4). Em França, o conceito de economia solidária partilha o desafio às antigas formas da economia social - focalizando princípios da democracia participativa interna e desenvolvimento sustentável - e ao próprio modelo de desenvolvimento capitalista. Laville (2007: 73) descreve a economia solidária como rearticulando os princípios económicos de reciprocidade, troca e redistribuição típicos da família/comunidade, mercado e Estado.

Ainda que o terceiro sector, o sector não lucrativo ou voluntário e a economia social sejam observações com importantes diferenças entre si, estas observações também têm aspectos em comum, fazendo parte de uma outra observação que tem como pano de fundo as funções e os limites/crise do Estado-Providência e um conjunto de discursos políticos acerca do modo como a sociedade, o Estado e a economia devem ser organizados. Apesar dos investigadores das diferentes tradições estarem em desacordo sobre que organizações incluir, eles concordam em medir o sector em termos da sua importância no emprego e na produção de serviços.

Finalmente, é inevitável falar de uma outra observação que descreve parte da realidade empírica que os anteriores conceitos pretendem observar e que também observa as observações que estes conceitos propõem. Tanto mais quanto alguns centros de investigação, projectos e debates foram entretanto rebaptizados para incorporarem o conceito de sociedade civil (Van Til e Ross, 2001). No entanto, este conceito é de todos o mais plurissemântico, com uma tradição teórica e política antiga e plural. ${ }^{8}$ Não é aqui o lugar para analisar o significado para a semântica da sociedade civil da adopção do conceito pelos investigadores do terceiro sector ${ }^{9}$ mas, sim, o significado da utilização do conceito de sociedade civil para observar o terceiro sector. Esta utilização torna-se possível pela recuperação do conceito

\footnotetext{
${ }_{8}$ Ver, a este propósito, Cohen e Arato, 1992.

9 Para uma discussão, ver Evers, 2008b.
} 
nos processos de transição democrática nos países da Europa Central e de Leste e de democratização e liberalização nos países do Sul. As observações propostas neste contexto são também de uma esfera entre o Estado e o mercado, mas a diferença que o conceito de sociedade civil oferece em relação aos anteriores conceitos é o questionamento da diferença entre político e social, e, sobretudo, da exclusão do político. Argumentam alguns dos seus autores que o conceito de sector não lucrativo se centra em demasia nos aspectos económicos e organizacionais, enquanto o conceito de sociedade civil e os seus indicadores permitem focar o lado político e cultural destas iniciativas (Heinrich, 2005: 219). Também para esta observação tem vindo a ser desenvolvido um Índice da Sociedade Civil (Civil Society Index), no contexto de um projecto desenvolvido pelo CIVICUS, ${ }^{10}$ que sublinha aspectos funcionais em detrimento de organizacionais e inclui 35 indicadores estruturais (económicos) e culturais (normas e valores) organizados em quatro dimensões num diamante da sociedade civil (Anheier, 2004). ${ }^{11}$ Este estudo está a ser desenvolvido em mais de 50 países. Definindo-o como "a esfera da sociedade entre Estado, mercado e família onde os cidadãos avançam os seus interesses”, pretende assim incluir formas de envolvimento não organizadas. ${ }^{12}$

\section{Os contextos e políticas de sector}

Ao longo da trajectória atrás descrita, governos, departamentos governamentais e indivíduos têm estado envolvidos nestas mesmas observações e nas observações destas observações. ${ }^{13}$ Em alguns países são criados departamentos e mesmo secretarias de Estado específicos para o sector, como a economia social, em França, depois a economia solidária em França e no Brasil, ou o terceiro sector em Inglaterra.

A recente difusão de pactos sociais entre governos e representantes do terceiro sector contribui para esta observação de separação. Estes pactos desenvolveram-se sobretudo a partir de finais da década de 1990, sendo o Compact inglês, proposto em 1996 no Deakin Report e assinado em 1998, apresentado como precursor. Entretanto foram assinados instrumentos idênticos no Canadá, na Estónia e em França, entre outros. Noutros países,

\footnotetext{
${ }^{10} \mathrm{http} / / /$ www.civicus.org/new/CSI_home.asp.

${ }_{11}$ A metodologia de recolha de informação é descrita em Heinrich, 2005; ver também CIVICUS, 2006.

12 Todavia, como observam Evers e Laville, 2004: 22, "existe uma tensão fundamental em tratar o terceiro sector como alternativa ao Estado e como uma expressão da sociedade civil".

13 Para alguns exemplos das várias formas institucionais de observação do sector, ver Bullain e Toftisova (2005) e CIRIEC (2000), que analisam o grau de institucionalização do sector em vários países.
} 
como na Dinamarca, na Croácia e na Hungria, esta observação do sector dá-se por via de um documento governamental sobre os princípios/regras do relacionamento entre o governo e o sector, sendo elaborados com participação das organizações do terceiro sector (OTS) (Bullain e Toftisova, 2005; Randma-Liiv et al., 2008). Também em Portugal, em 1996, se assinou um Pacto de Cooperação para a Solidariedade Social entre o governo, as autarquias e representantes das Instituições Particulares de Solidariedade Social.

As organizações internacionais têm também proposto observações heterogéneas em relação ao sector. Já foi atrás referido o envolvimento das Nações Unidas no desenho da conta satélite. A OCDE tem publicado estudos sobre o sector não lucrativo e as empresas sociais. A OIT tem-se preocupado com as questões do trabalho, tendo financiado um estudo sobre o trabalho no sector não lucrativo (Anheier et al., 2003) e colabora agora com o Projecto da Johns Hopkins na identificação de indicadores sobre voluntariado. A semântica do Banco Mundial nas suas intervenções nos países da América Latina, Ásia, África e Europa Central e de Leste tem sido sobretudo em torno do conceito de sociedade civil. Nas instituições europeias, ainda que exista um défice de encastramento institucional do "sector", este tem sido reconhecido através do apoio à investigação, bem como às organizações através dos programas e iniciativas comunitários. Proliferam diferentes semânticas de sector em diferentes espaços. A da sociedade civil é usada pelo Comité Económico e Social (CES) e pela DG V no contexto do diálogo cívico e social (Smismans, 2003) e no Livro Branco da Governação Europeia a sociedade civil é citada num duplo papel: o de fornecedora de serviços e o de dar voz às preocupações dos cidadãos (Armstrong, 2002). A da economia social também tem presença desde há muito, nomeadamente numa Unidade da Economia Social na DG XXIII, sendo referida em documentos e políticas europeias como as de emprego ou de luta contra a pobreza e no modelo social europeu, entre outras referências. A recente Resolução do Parlamento Europeu apela ao reconhecimento da economia social ao nível jurídico e estatístico, como parceiro social e como actor na Estratégia de Lisboa. ${ }^{14}$

As diferentes observações do terceiro sector devem ser interpretadas contextualmente tendo em consideração as configurações específicas da relação Estado/economia/comunidade/sociedade civil, bem como as diferentes tradições e projectos políticos acerca destas relações. Enquanto a

${ }_{14}$ Resolução do Parlamento Europeu, de 19 de Fevereiro de 2009, sobre a economia social (2008/2250(INI)). 
semântica do terceiro sector emerge nos anos 1970 nos EUA e no Reino Unido num contexto de crítica e crise do Estado-Providência, a semântica da economia social surge em França e tem ressonância na Europa continental no contexto da crise do emprego. Todavia, nos países escandinavos não existiu durante muito tempo uma semântica de sector e as organizações foram vistas como advogadas do Estado-Providência. Só na década de 1990 surge politicamente este actor como suplemento do sector público e os investigadores se começam a interessar pelo terceiro sector e as associações cívicas (Matthies, 2006).

Verificam-se também variações tendo em conta os diferentes modelos de relação entre o terceiro sector e o Estado. ${ }^{15}$ A tradição liberal dos países anglo-saxónicos e o carácter residual da protecção social é favorável às separações entre Estado, mercado e comunidade, verificando-se que algumas das iniciativas de afirmação do sector surgem na sequência do questionamento das suas fronteiras e especificidade. No caso da Europa continental, as realidades são mais diversas mas o papel do Estado é mais proeminente e menos contestado. Em França, onde existe uma forte tradição de intervenção pública na área social, a observação de sector desenvolve-se a partir da economia e da observação de economias alternativas. Em alguns países do modelo conservador/corporativo não se afirmou qualquer semântica global de sector até à década de 1990. Isto pode ser compreendido pela relação entre estas organizações e o Estado, sobretudo na área do bem-estar, com delegação de responsabilidades públicas nestas organizações, definidas como contribuindo para o interesse geral, e a vigência do princípio da subsidiariedade. Este é o caso de Portugal, onde as organizações que actuam nas áreas de bem-estar não necessitam de integrar um sector mais amplo com vista a defender a sua posição.

Em Portugal não existe qualquer paralelo com a construção do sector à dimensão do que aconteceu em alguns dos países anteriormente referidos. Tal prende-se com características que podemos associar à natureza do Estado-Providência português. Assim, são várias as semânticas de sector existentes, nenhuma predominando e todas fortemente influenciadas pelas experiências estrangeiras. Mantém-se a heterogeneidade das abordagens que buscam referências em diferentes tradições teóricas e políticas. Grupos de organizações estruturam-se em redes, plataformas, federações e confederações sectoriais autónomas, enquanto noutras áreas as organizações

15 Para uma análise das diferenças do terceiro sector no contexto dos diferentes modelos de bemestar e da literatura a este respeito, consultar Ferreira, 2006. Para uma análise das diferenças contextuais do terceiro sector a partir da abordagem das variedades do capitalismo ver Almeida, 2008. 
existem em torno de organismos públicos. Não existe, em termos de observação de sector, qualquer tentativa de agregar estas organizações em torno de uma descrição comum. Os únicos estudos de carácter geral foram os que decorreram da integração de Portugal em projectos internacionais, o estudo do CIRIEC (2000) sobre o terceiro sistema e, mais recentemente, o Projecto da Johns Hopkins (Franco et al., 2005). Estes dois estudos internacionais permitem a construção de um discurso sobre o peso económico do(s) sector(es) em Portugal, mas torna-se evidente que eles não nascem da mesma dinâmica que motivou a "invenção" de um sector em alguns países, conforme descrito atrás. Em suma, o "sector" não parece interessado em inventar-se em Portugal, nem os governos demonstram interesse nas oportunidades oferecidas pela semântica de um "sector".

\section{O terceiro sector como observação de segunda ordem}

Ao nível do concreto complexo, existe uma variedade de organizações, práticas, racionalidades e trajectórias associadas a uma organização ou a um grupo de organizações específico. Existe a ideia de que as organizações partilham identidades e interesses com organizações semelhantes, que podem variar num mesmo momento consoante as interacções ou ao longo do tempo, e relacionam-se com uma pluralidade de organizações públicas e privadas e com uma grande variedade de públicos interessados. Esta diversidade é experimentada pelas organizações e moldada pelos quadros institucionais, nomeadamente pela existência de organizações federativas, de legislação ou de circulação de informação. No mesmo sentido em que as organizações e iniciativas são orientadas para a redução da sua complexidade através da adesão a identidades mais abstractas, locais, sectoriais ou federativas, são ao mesmo tempo empurradas para a heterogeneidade na sua relação com outras organizações e racionalidades no seu ambiente e nos seus processos.

Uma das propostas de abordagem que procura dar conta da diversidade empírica sem abandonar a observação de sector observa as OTS como "misturas nas misturas de bem-estar" (Evers e Laville, 2004). Assim, diferentes OTS apresentam misturas particulares das racionalidades do Estado, mercado e comunidade, consoante as suas relações específicas (Brandsen et al., 2005; Evers, 2008a). Assim, a descrição de terceiro sector está dependente de um conjunto de observações acerca do modo como o mundo está organizado. O terceiro sector surge assim que as separações entre mercado, Estado e (por vezes) comunidade, público e privado, formal e informal estejam estabelecidas, e oferece uma rearticulação destas. É porque estas separações existem - e existem com diferentes graus e desenhos em diferentes sociedades - que é possível descrever o terceiro sector como ocupando 
o espaço no centro de um triângulo cujos vértices são constituídos pelo Estado, mercado e comunidade, o qual tem no seu centro associações que são privadas, formais e não lucrativas, rodeadas por outras OTS onde as diferenças entre formal/informal, público e privado, lucrativo e não lucrativo são mais ténues (ver Pestoff, 1998; Evers e Laville, 2004).

A forma da observação utilizada na descrição do terceiro sector - o que é e o que não é - é um descritor do terceiro sector tanto quanto o é do Estado e do mercado, pois é feita a partir do ponto de vista de um determinado observador. Assim, em algumas classificações do sector, o mercado orienta-se pelo lucro enquanto o terceiro sector não busca o lucro, as relações no Estado são obrigatórias enquanto no terceiro sector são voluntárias, o terceiro sector é formal e organizado enquanto a comunidade é informal e desorganizada. Assim, enquanto conceito relacional, o terceiro sector estabelece fronteiras que também definem o Estado, o mercado e a comunidade, isto é, os aspectos seleccionados para constituírem o Estado, o mercado e a comunidade como separados na descrição de terceiro sector. Porém, o terceiro sector também é uma observação do Estado, do mercado e da comunidade, porque na sua descrição também inclui aspectos destes, como a produção de bens públicos, tal como o Estado, o carácter voluntário da participação, tal como o mercado, a solidariedade, tal como a comunidade. As teorizações em torno dos fracassos do Estado, do mercado ou da comunidade, e do papel do terceiro sector, fundamentadas nas observações das separações, são observações do Estado e do mercado, reflectindo e sendo constitutivas das observações destes e do terceiro sector. Isto acontece nas distinções da economia e do Estado em relação ao sector (Weisbrod, 1977; Hansmann, 1980) e também da comunidade (Vibert, 2004), mesmo que se deva contemplar a dupla semântica de comunidade recuperada recentemente para o conceito de capital social na distinção entre bridging e bonding (Wuthnow, 2002). Todavia, mesmo em relação à comunidade, as observações do terceiro sector podem também apontar os seus fracassos, como é o caso dos identificados por Salamon (1987) quando descreve os fracassos da acção voluntária que justificaram a intervenção do Estado na esfera do bem-estar: insuficiência filantrópica, paternalismo, particularismo e excesso de amadorismo (Salamon, 1987).

Assim, para a observação de cada um dos sectores, a observação do terceiro sector permite apontar os fracassos vistos a partir de cada observação, mas também os sucessos nas características que selecciona de cada um dos sectores. Esta semântica não ocupa apenas o espaço da academia ou das estratégias de invenção de um sector por federações e confederações, mas encontra-se também nas autodescrições de organizações. 
Semântica das observações do terceiro sector

\begin{tabular}{|c|c|c|c|}
\hline & Estado & Mercado & Comunidade \\
\hline $\begin{array}{l}\text { Fracassos que o } \\
\text { terceiro sector } \\
\text { observa }\end{array}$ & $\begin{array}{l}\text { Incapacidade de respon- } \\
\text { der a todas as expec- } \\
\text { tativas da população; } \\
\text { Burocracia; } \\
\text { Rigidez; } \\
\text { Falta de inovação; } \\
\text { Compulsão e interven- } \\
\text { ção de cima para baixo }\end{array}$ & $\begin{array}{l}\text { Incapacidade de pro- } \\
\text { duzir bens públicos } \\
\text { dados os critérios de } \\
\text { lucro; } \\
\text { Falta de confiança; } \\
\text { Atomização nas rela- } \\
\text { ções sociais; } \\
\text { Curta duração }\end{array}$ & $\begin{array}{l}\text { Dificuldade de articular } \\
\text { a solidariedade em } \\
\text { comunidades diversas; } \\
\text { Desigualdade e depen- } \\
\text { dência nas relações } \\
\text { sociais; } \\
\text { Incapacidade de res- } \\
\text { ponder a todas as ne- } \\
\text { cessidades; } \\
\text { Incapacidade de indivi- } \\
\text { dualizar e formalizar } \\
\text { as relações sociais }\end{array}$ \\
\hline $\begin{array}{l}\text { Elementos que } \\
\text { recolhe }\end{array}$ & $\begin{array}{l}\text { Produção de bens pú- } \\
\text { blicos ou de interesse } \\
\text { geral }\end{array}$ & $\begin{array}{l}\text { Liberdade, inovação, } \\
\text { flexibilidade }\end{array}$ & Solidariedade, confiança \\
\hline $\begin{array}{l}\text { Articulações que } \\
\text { propõe }\end{array}$ & $\begin{array}{l}\text { Partindo da ideia de } \\
\text { bem comum e com } \\
\text { mecanismos flexíveis } \\
\text { de decisão, permite } \\
\text { que indivíduosecomu- } \\
\text { nidades exprimam as } \\
\text { suas necessidades, } \\
\text { sendo capaz de jus- } \\
\text { tificar a responsabili- } \\
\text { dade da comunidade } \\
\text { e dos indivíduos pela } \\
\text { participação no bem } \\
\text { comum. }\end{array}$ & $\begin{array}{l}\text { Usa instrumentos do } \\
\text { mercado e concebe os } \\
\text { actores sociais como } \\
\text { autónomos, ao mes- } \\
\text { mo tempo que de- } \\
\text { senvolve mecanismos } \\
\text { de confiança entre os } \\
\text { membros e critérios } \\
\text { substantivos em nome } \\
\text { do interesse comum } \\
\text { ou das necessidades } \\
\text { de um grupo. }\end{array}$ & $\begin{array}{l}\text { Com base em relações } \\
\text { expressivas e de obri- } \\
\text { gação mútua, desen- } \\
\text { volve mecanismos de } \\
\text { troca para permitir a } \\
\text { possibilidade de ex- } \\
\text { pressão de necessida- } \\
\text { des individuais (pode } \\
\text { incluir equivalências } \\
\text { desiguais) ou definir } \\
\text { a sua visão do bem } \\
\text { comum. }\end{array}$ \\
\hline
\end{tabular}

$\mathrm{Na}$ linha do que tenho vindo a discutir, proponho que o terceiro sector seja analisado não só como uma reentrada no Estado ou no mercado ou na comunidade mas, sim, uma observação das separações entre Estado, mercado e comunidade. Ou seja, uma observação de segunda ordem destas separações. Assim, o terceiro sector e as relações sociais descritas por este conceito observam não só os sistemas e subsistemas funcionalmente diferenciados, ou os diferentes modos de coordenação ou governação - conforme a tradição teórica -, mas também a complexidade que resulta das observações que produzem a diferenciação funcional. Por isso, o terceiro sector pode ser visto também como um mecanismo de governação dos diferentes modos de governação, como observa Enjolras ao caracterizar a economia social como um mecanismo de coordenação que cria compromissos entre diferentes mecanismos de coordenação ultrapassando os seus 
fracassos. Este autor refere que a economia social reconcilia mercado e Estado, transformando o interesse privado em interesse comum através de controlo democrático e de debate, reconcilia a tensão entre mercado e reciprocidade, permitindo autonomia no contexto de relações de solidariedade pessoais, e reduz a tensão entre hierarquia e reciprocidade, através da personalização e individualização de serviços, e considerando as particularidades das comunidades, enquanto permite a manutenção da igualdade no acesso aos serviços (2002: 40-43). Para além disso, o que o terceiro sector traz de novo é a integração da observação da comunidade com a observação do Estado e do mercado, formulando não só a observação do Estado e do mercado observando-se mutuamente, mas também a observação do Estado e do mercado pela comunidade e esta pelos anteriores.

Ao nível da análise concreta de organizações também é possível encontrar alusão ao papel de observação de diferentes sistemas pelas OTS e a integração destas observações nos processos organizacionais. Muitas organizações estão acopladas a mais do que um subsistema ou sector (Estado, economia, direito, religião, saúde, educação, bem-estar, pessoas e relações interpessoais...), sendo caracterizadas por objectivos, identidades, recursos, estruturas institucionais, culturas e públicos heterogéneos e, por vezes, contraditórios. Isto gera a natureza híbrida ${ }^{16}$ das OTS, a qual gera tensões e pressões contraditórias nas organizações resultantes do encontro de racionalidades diferentes (Evers, 1995; Brandsen et al., 2005). Também nas concepções dos sistemas complexos autopoiéticos, as organizações são concebidas como produzindo o acoplamento de sistemas operacionalmente fechados (Luhmann, 2005), pois relacionam-se com diversos sistemas. Em muitas organizações existe um sistema que é dominante, mas nas organizações híbridas nenhum dos sistemas prevalece em termos de determinar as suas operações principais. Assim, por conterem observações de diferentes sistemas, as OTS podem tornar visível o que não pode ser observado pelos sistemas fechados, incluindo a complexidade que criam no ambiente com as suas operações e o modo como afectam a vida das pessoas e grupos sociais.

A lei da variedade requerida, formulada por Ashby (1971), refere que, para lidar com a complexidade do ambiente, determinado sistema tem que possuir um grau de complexidade suficiente, capaz de recodificar a complexidade ambiental em complexidade organizada com a qual o sistema

${ }_{16}$ Brandsen et al. (2005: 751) definem híbridos como "arranjos heterogéneos, caracterizados por misturas de origens puras e incongruentes, tipos (ideais), 'culturas', 'mecanismos de coordenação', 'racionalidades' ou lógicas de acção". 
consegue lidar. O uso estratégico da hibridização poderá ser um mecanismo que permite a manutenção da complexidade necessária para lidar com ambientes muito complexos. Assim, com recurso à variedade interna, um determinado sistema (ou organização) pode observar os fracassos resultantes de outros sistemas e organizações e procurar articular as várias lógicas sem as reduzir a uma única, pois o que interessa não é a lógica a partir da qual se observa mas o facto de se observar.

Concebida em termos da semântica mais abstracta de um terceiro sector e do papel desta semântica enquanto observação de observações, a variedade oferecida pelas descrições do terceiro sector permite observar a complexidade, afigurando-se, por isso, um mecanismo de governação societal que permite a não redução da variedade requerida em sociedades muito complexas. Ao nível das organizações coloca-se também a questão de saber como estas conseguem manter as diferentes lógicas em tensão sem que nenhuma tenha prevalência sobre as outras. Algumas das observações acerca da configuração das OTS apontam algumas pistas de reflexão, particularmente entre os autores que se dedicaram ao estudo da forma da associação. Enjolras (1998: 229), por exemplo, aponta para a especificidade da forma associativa, constituída por uma assembleia-geral e uma direcção eleitas, permitindo a formação discursiva da vontade, onde a possibilidade de universalização de interesses particulares é testada, através de processos internos de deliberação, com vista à formação de um consenso racional. Todavia, também poderíamos argumentar que o diálogo tem que ser interrompido em algum momento para que sejam tomadas decisões e a vontade consensual tenderá a favorecer determinados interesses. Assim sendo, poderá não ser a possibilidade de atingir um consenso que faz a eficácia da associação, mas o facto de permitir que uma variedade de visões do mundo e interesses se observem mutuamente e confrontem e que se tomem decisões que também possam ser observadas. Ideias sobre a auto-organização dos sistemas complexos, focando a possibilidade de comunicação entre sistemas fechados e da necessária manutenção de variedade capaz de absorver a complexidade do ambiente, preocupam-se também com a possibilidade de comunicação entre sistemas autopoiéticos, mas apontam para possibilidades de comunicação, mesmo que estas sejam opacas para o observador (ver Baecker, 2002).

\section{Conclusão}

Apresentei neste texto uma proposta de análise do terceiro sector e dos seus equivalentes partindo dos contributos da visão relacional estratégica e das teorias dos sistemas complexos. Adoptei o conceito de observação como base para a análise. O texto desenvolveu-se em torno de duas utilizações 
desse conceito, o das observações da autora das observações de terceiro sector e o do papel do terceiro sector enquanto observador e observação. Através da minha observação procurei, sobretudo, evidenciar a contingência das selecções que criam o terceiro sector, mas também a lógica estratégica e contextual associada a estas selecções, permitindo justificar a importância que a semântica de sector adquiriu desde a crítica e crise do Estado-Providência.

Defendi que a ideia de sector é uma construção discursiva que emergiu de estratégias particulares de determinados actores sociais, encontrou condições estruturais de ressonância e foi amplamente adoptada, inspirando práticas para a sua materialização. Tracei as origens do termo terceiro sector, bem como dos seus equivalentes "sectoriais", mostrando que o trabalho de definição de fronteiras através de definições e medidas está permanentemente incompleto, pois insere-se nas estratégias dos actores. Enquanto o termo terceiro sector possui uma expressão que é sobretudo transnacional, idênticas observações de sector são mais localizadas, como por exemplo sector não-lucrativo, sector voluntário, sector independente ou intermediário. A sua semântica descreve fronteiras entre Estado, mercado e comunidade, público e privado, e outras separações típicas da modernidade.

Coloquei-me como observadora da diferenciação funcional dos sistemas fechados e da complexidade criada pelas operações de redução de complexidade dos sistemas e, em particular, da possibilidade do terceiro sector se colocar como observação de segunda ordem, o que permite rearticular as observações dos sistemas oferecendo observação mútua através da variedade.

A segunda utilização do conceito de observação implica observar as observações do terceiro sector, com especial atenção ao modo como o sector se afirma afirmando as fronteiras entre Estado, mercado e comunidade e, ao mesmo tempo, se insere no espaço de discursos sobre misturas, hibridização e diluição de fronteiras. Emerge assim um paradoxo, pois a hibridização requer, para existir, a existência de fronteiras e sectores. Assim, opto por observar o terceiro sector e as organizações e interacções por ele descritas como mecanismos de governação que permitem actuar no espaço desse paradoxo na medida em que não só estabelecem fronteiras como operam a sua rearticulação. A noção de auto-organização, proveniente das teorias dos sistemas complexos, encontra ressonâncias nas teorias que apontaram para a importância do terceiro sector e das organizações como espaço de diálogo entre lógicas diferentes e irredutíveis. Aqui, um dos conceitos que permitem perceber os efeitos destas operações sem reduzir o mundo à nossa capacidade de o compreender através das explicações de causalidade é o de "dança", proposto por Baecker (2002), um conceito que prescinde das 
explicações que implicam causalidades lineares. Além disso, a cibernética de segunda ordem que observa o significado estratégico das definições existentes também evita a tentação de uma nova grande narrativa.

Neste contexto, na medida em que se torna cada vez mais evidente a contingência das observações da ciência moderna, os estudos sobre o terceiro sector oferecem uma variedade cujas potencialidades ainda não foram cabalmente exploradas, debatendo-se com a ausência de instrumentos analíticos capazes de dar conta das potencialidades da variedade de observações do sector. Assim, a vantagem e a limitação deste campo de investigação é a impossibilidade de se fixar numa disciplina específica, sendo antes observado a partir da economia, da ciência política, da antropologia, da história, da sociologia, da gestão, etc.

O conceito de observação, no centro deste texto, operacionaliza a abordagem relacional estratégica enquanto tentativa de ultrapassar teoricamente a dualidade entre acção e estrutura, oferecendo-se à observação como sendo, simultaneamente, estrutura e estratégia. Uma observação selecciona a partir das selecções disponíveis, constituindo-se e ao seu ambiente no acto de observar. Mas no mesmo acto de se tornar observação define-se também como contingente, deixando visíveis as observações que exclui, não a si própria mas a outras observações, que são também assim determinadas nas suas observações. Por isso se propõe um passo em frente a partir da sociologia luhmaniana, valorizando as observações de fracasso, constitutivas, aliás, da semântica do terceiro sector, não como mero ruído nos sistemas, mas como a fonte de variedade requerida articulável em espaços específicos, ou seja, a condição para a governação da complexidade contemporânea.

\section{Referências bibliográficas}

Almeida, Vasco (2008), "Capitalism, Institutional Complementarities and the Third Sector. The Private Institutions for Social Solidarity (IPSS) in Portugal”, ISTR Conference Working Papers, Volume VI. Disponível em: http://www.istr.org/conferences/barcelona/WPVolume/ index.htm (acedido em Maio de 2009).

Amin, Ash et al. (2002), Placing the Social Economy. London: Routledge.

Andersen, Niels Åkerstrøm (2000), "Political Administration", MPP Working Paper

No. 5/2000, Copenhagen Business School.

Anheier, Helmut (2004), Civil Society: Measurement, Evaluation, Policy. London: Earthscan. Anheier, Helmut et al. (2003), Work in the Non-profit Sector: Forms, Patterns and Methodologies. Geneva: OIT.

Armstrong, Kenneth (2002), "Rediscovering Civil Society: The European Union and the White Paper on Governance", European Law Journal, 8(1), 102-132. 
Ashby, William (1971), An Introduction to Cybernetics. London: Chapman \& Hall. Ávila, Rafael; Monzón Campos, José Luis (2006), The Social Economy in the European Union. Liège: CIRIEC/The European Economic and Social Committee.

Baecker, Dirk (2002), "The Joker in the Box or the Theory Form of the System”, Cybernetics and Human Knowing, 9(1), 51-74.

Barea, José; Monzón Campos, José Luis (2006), Manual for Drawing up the Satellite Accounts of Companies in the Social Economy. Liège: CIRIEC.

Borzaga, Carlo; Defourny, Jacques (orgs.) (2001), The Emergence of Social Enterprise. London: Routledge.

Brandsen, Taco et al. (2005), "Griffins or Chameleons? Hybridity as a Permanent and Inevitable Characteristic of the Third Sector", International Journal of Public Administration, 28(9), 749-765.

Bullain, Nilda; Toftisova, Radost (2005), "A Comparative Analysis of European Policies and Practices of NGO-Government Cooperation”, International Journal of Not-ForProfit Law, 7(4), 64-112.

Chanial, Philippe; Laville, Jean-Louis (2005), “L'Economie sociale et solidaire en France", in Jean-Louis Laville et al. (orgs.), Action publique et économie solidaire: Une perspective internationale. Ramonville Saint-Agne: Érès.

CIRIEC (2000), The Entreprises and Organisations of the Third System: A Strategic Challenge for Employment. Liège: CIRIEC.

CIVICUS (2006), Civicus Civil Society Index: Preliminary Findings - Phase 2003-2005. Disponível em: http://www.civicus.org/new/media/ICSI\%20paper.pdf?07c23fc490fb56da 2 8db023ad7e04d9d=9ef5984e185 c499eaf023 efce723e372 (acedido em Abril de 2009).

Cohen, Jean; Arato, Andrew (1992), Civil Society and Political Theory. Cambridge, Mass.: MIT Press.

Commission on the Future of the Voluntary Sector (1996), Meeting the Challenge of Change. Voluntary Action into the 21st Century. London: NCVO Publications.

Defourny, Jacques; Monzón Campos, José Luis (orgs.) (1992), Économie Sociale-Entre économie capitaliste et économie publique/The Third Sector - Cooperative, Mutual and Nonprofit Organizations. Brussels: De Boeck.

Delors, Jacques (2004), “The European Union and the Third Sector”, in Adalbert Evers; Jean-Louis Laville (orgs.), The Third Sector in Europe. Cheltenham; Northampton, Mass.: Edward Elgar Publishing.

DiMaggio, Paul; Powell, Walter W. (1983), “The Iron Cage Revisited: Institutional Isomorphism and Collective Rationality in Organizational Fields", American Sociological Review, 48(2), 147-160.

Enjolras, Bernard (1998), "Crise de l'État-providence, lien social et associations: éléments pour une socio-économie critique", in Jean-Louis Laville; Allain Caillé (orgs.), Une seule solution, l'association? Socio-économie du fait associatif, Revue du MAUSS, 11, 223-236. 
Enjolras, Bernard (2002), L'économie solidaire et le marché : Modernité, société civile et démocratie. Paris: l'Harmattan.

Evers, Adalbert (1995), "Part of the Welfare Mix: The Third Sector as an Intermediate Area", Voluntas, 6(2), 159-182.

Evers, Adalbert (2008a), "Hybrid Organisations. Background, Concepts, Challenges", in Stephen Osborne (org.), The Third Sector in Europe: Prospects and Challenges. Abingdon: Routledge, 279-292.

Evers, Adalbert (2008b), “Observations on Uncivility - Points of Reference to Blind Spots in Third Sector Research”, resposta a Victor Pérez-Díaz na ISTR Eighth International Conference 2nd EMES-ISTR European Conference, Barcelona, 9-12 Julho.

Evers, Adalbert; Laville, Jean-Louis (orgs.) (2004), The Third Sector in Europe. Cheltenham; Northampton, Massachusetts: Edward Elgar Publishing.

Ferreira, Sílvia (2005), "O que tem de especial o empreendedor social? O perfil de emprego do empresário social em Portugal”, Oficina do CES, 223.

Ferreira, Sílvia (2006), "The South European and the Nordic Welfare and Third Sector Regimes - How Far Were We from Each Other?”, in Aila-Leena Matthies (org.), 299-323.

Franco, Raquel et al. (2005), O sector não-lucrativo português numa perspectiva comparada. Lisboa/Baltimore: Universidade Católica Portuguesa / Johns Hopkins University.

Gaiger, Luís Inácio (2000), “As organizações do terceiro setor e a economia popular solidária”, 4. ${ }^{a}$ Conferência Internacional da ISTR, Dublin, Julho de 2000.

Hansmann, Henry (1980), "The Role of Nonprofit Enterprise”, Yale Law Journal, 89(3), 835-901.

Heinrich, Volkhart (2005), "Studying Civil Society across the World: Exploring the Thorny Issues of Conceptualization and Measurement”, Journal of Civil Society, 1(3), 211-228.

Jessop, Bob (2007), State Power: A Strategic Relational Approach. Cambridge: Polity Press.

Kendall, Jeremy (2000), "The Mainstreaming of the Third Sector in to Public Policy in England in the Late 1990s: Whys and Wherefores", Policy E Politics, 28(4), 541-563.

Knight, Barry (1993), Voluntary Action. London: Home Office.

Kramer, Ralph (1998), Nonprofit Organizations in the 21st Century: Will Sector Matter? Washington, D.C: The Aspen Institute.

Laville, Jean-Louis (org.) (2007), L'économie solidaire: Une perspective internationale. Paris: Hachette Littératures.

Laville, Jean-Louis et al. (2000), "Third System: A European Definition”, in CIRIEC (org.), The Entreprises and Organisations of the Third System: A Strategic Challenge for Employment. Liège: CIRIEC.

Levitt, Theodor (1973), The Third Sector: New Tactics for a Responsive Society. New York: Amacom. 
Luhmann, Niklas (1995a), Social Systems. Stanford: Stanford University Press.

Luhmann, Niklas (1995b), "The Paradoxy of Observing Systems", Cultural Critique, 31, The Politics of Systems and Environments, Part II, 37-55.

Luhmann, Niklas (2005), Organización y decisión. Autopoiesis, acción y entendimiento comunicativo. México/Barcelona: Universidad Iberoamericana/Anthropos.

Matthies, Aila-Leena (2006), "Report of the 'State of Knowledge' - Project on Research of Third Sector in the Area of Welfare Services in Nordic Countries", in Aila-Leena Matthies (org.), 13-155.

Matthies, Aila-Leena (org.) (2006), Nordic Civic Society Organisations and the Future of Welfare Services. A Model for Europe?. Copenhagen: Nordic Council of Ministers.

Pestoff, Victor (1998), Beyond the Market and State: Social Enterprise and Civil Democracy in a Welfare Society. Aldershot, Hants, England: Brookfield, Vt. / EUA: Ashgate Pub.

Randma-Liiv, Tiina et al. (2008), "Institutionalising Relationships Between Government and the Third Sector: The Case of the Estonian 'Compact'”, in Stephen Osborne (org.), The Third Sector in Europe: Prospects and Challenges. Abingdon: Routledge, 256-276.

Salamon, Lester (1987), "Partners in Public Service: The Scope and Theory of Government-Nonprofit Relations”, in Walter Powell (org.), The Nonprofit Sector: A Research Handbook. New Haven / London: Yale University Press, 99-117.

Salamon, Lester et al. (1999), Global Civil Society: Dimensions of the Nonprofit Sector. Baltimore: Center for Civil Society Studies.

Salamon, Lester et al. (2004), Global Civil Society. Volume 2, Dimensions of the Nonprofit Sector. Bloomfield, Conn.: Kumarian.

Salamon, Lester; Anheier, Helmut (1992), "In Search of the Nonprofit Sector II: The Problem of Classification", Working Papers of the Johns Hopkins Comparative Nonprofit Sector Project, no. 3. Baltimore: The Johns Hopkins Institute for Policy Studies.

Santos, Boaventura de Sousa (2006), A gramática do tempo: Para uma nova cultura política. Porto: Afrontamento, 317-349.

Smismans, Stijn (2003), "European Civil Society: Shaped by Discourses and Institutional Interests”, European Law Journal, 9(4), 473-495.

Smith, David (2000), Grassroots Associations. Thousand Oaks: Sage Publications.

Spencer Brown, George (1969), Laws of Form. New York: Julian.

Van Til, Jon; Ross, Steven (2001), "Looking Backward: Twentieth-Century Themes in Charity, Voluntarism, and the Third Sector", Nonprofit and Voluntary Sector Quarterly, 30(1), 112-129.

Vibert, Stéphane (2004), "La communauté est-elle l'espace du don? De la relation, de la forme et de l'institution sociales (1re partie)", Revue du MAUSS, 24, 353-374. Weisbrod, Burton (1977), The Voluntary Nonprofit Sector. Lexington: D.C. Heath \& Company. 
Wolfenden Committee (1978), The Future of Voluntary Organisations. London: Croom Helm.

Wuthnow, Robert (2002), "Religious Involvement and Status-Bridging Social Capital”, Journal for the Scientific Study of Religion, 41(4), 669-684.

Young, Dennis (2003), "New Trends in the US Non-profit Sector: Towards Market Integration?" in OCDE, The Non-profit Sector in a Changing Economy. Paris: OCDE, 61-77. 